\title{
Skid resistance properties against RAP content change in surface asphalt mixture
}

\author{
M. Pomoni, C. Plati \& A. Loizos \\ Laboratory of Pavement Engineering, National Technical University of Athens (NTUA), Greece
}

\begin{abstract}
Many countries use the Reclaimed Asphalt Pavement (RAP) into traditional asphalt mixtures for road surface layers, at a content of approximately $10-30 \%$. So far, many studies have investigated the performance of these mixes dealing mainly with existing fundamental issues of the mix design process. The present study focuses on their functional performance and most specifically, on their skid resistance properties when used at surface layers containing RAP. To that purpose, a laboratory process is designed for the fabrication of both RAP-content asphalt mixtures and traditional Hot-Mix-Asphalt (HMA) mixtures in order to assess their skid resistance performance. HMA mixes are used as reference considering that these mixtures are most often used for road construction. The HMA was taken from an insitu layering process. The emphasis was put on the impact of weather changes on materials' performance. In an attempt to reflect field conditions, a laboratory simulation was performed to consider some weather changes (i.e. temperature, raining effect and contamination). Skid resistance measurements were performed on the fabricated specimens using the British Pendulum Tester. The analysis results showed promising aspects for the use of RAP in wearing courses for all the followed simulations. Overall, it is argued that the use of RAP did not appear to weaken skid resistance levels, providing as such an additional merit in its use apart from its low carbon footprint, in opposition to the production of new HMA mixes.
\end{abstract}

Keywords: RAP, skid resistance, weather changes, laboratory simulation, British Pendulum Tester

\section{BACKGROUND \& OBJECTIVE}

Recycling of pavement materials is a common practice nowadays in an effort to limit, as much as possible, the use of virgin materials. This procedure started from the early 70 s due to the high cost of crude oil during the Arab oil embargo (Federal Highway Administration, 2011). Therefore, there have been numerous applications in a worldwide scale, not only for pavement rehabilitation projects but also for new road construction activities.

The most popular recycled pavement material is the Reclaimed Asphalt Pavement (RAP), which is extensively used in asphalt mixtures during the last decades. However, besides its sustainable identity, there are concerns amongst the agencies regarding its long-term performance and the long-term cost-effectiveness that can be achieved over the pavement service life (Sotoodeh-Nia et al. 2019). The main concerns refer to the rheological properties of the RAP material that progressively change. Basically, the different properties between the fresh HotMix Asphalt concrete (HMA) and the RAP have produced evidence regarding the susceptibility of the final mixture to low temperatures and fatigue cracking (Sotoodeh-Nia et al. 2019, Al-Qadi et al. 2007). Hence, several approaches have been investigated for the incorporation 
of RAP material in HMA, especially during pavement rehabilitation, where the upper asphalt layer is usually replaced. Focusing on the surface layer and according to FHWA (2011), it seems that the majority of highway agencies in the US tend to use RAP materials at a percentage of $10 \%-30 \%$. However, the usage of contents $10 \%-20 \%$ is more usual (Figure 1).

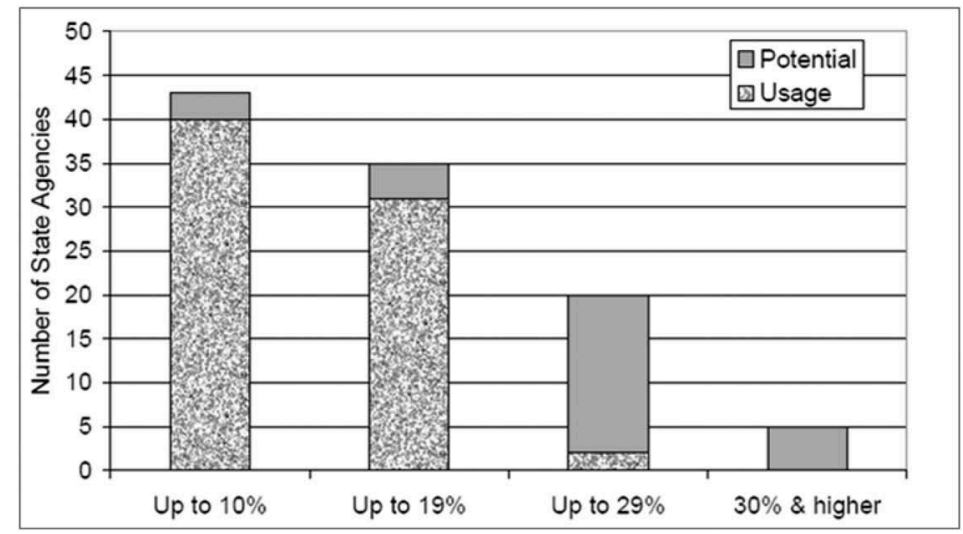

Figure 1. Usage and potential of RAP material (\%) in the surface layer (FHWA, 2011).

Knowledge on the usage of RAP on the surface layer is mainly concentrated around the mechanical properties of the asphalt mixture. However, considering that the surface layer comes in direct contact with the tyres of the moving vehicles, the provided tyre-pavement contact is also a matter of concern (Plati et al. 2020a). The pavement wearing course should have appropriate characteristics for providing adequate skid resistance with regards to road safety requirements under various weather conditions. Adequate skid resistance levels enable vehicles to speed up, brake, slow down and move safely around curvatures (Flintch et al. 2012).

With regards to the above, the present study aims to provide some preliminary findings on the skid resistance performance of HMA wearing courses containing RAP. This study is part of an ongoing research that aims at a more thorough assessment of the skid resistance performance of pavement surfaces consisting of both conventional and sustainable materials. To meet the study goals, asphalt mixtures with variable RAP contents were fabricated in the laboratory in order to meet the specifications of wearing courses, while a laboratory procedure to simulate weather changes was designed and followed.

\section{SKID RESISTANCE \& WEATHER CHANGES}

The two basic components that are critical to the skid resistance development are: macrotexture and microtexture. They are both interrelated to the properties of the materials used for pavement surface construction (Plati et al. 2019, Flintch et al. 2012). In particular, aggregate gradation in the asphalt mixture, air void content and binder properties mainly influence the pavement macrotexture, while aggregates mineralogy and their shape mainly affect microtexture levels (Kane and Edmonsson 2020, White et al. 2019, Plati et al. 2017). Towards this, it is obvious that the material properties used for the wearing course are determinant for the provided skid resistance.

Besides material properties, tyre-pavement interaction is susceptible to weather changes as well. This means that temperature changes, raining events and the presence of dust or snow on the pavement surface can affect the provided skid resistance (Plati et al. 2020b). On the one hand, this sort of weather changes affects the tyre-pavement contact, as is the case of water presence beneath the tyre tread. On the other hand, the asphalt mixture characteristics 
influence the tyre-pavement contact during various weather conditions. For instance, the aggregate asperities (level of microtexture) can penetrate the film of water during a rainfall and enable the tyre tread to directly contact the pavement surface (Plati et al. 2020b, Do et al. 2013).

In general, skid resistance level is subjected to variations throughout a year due to the seasonal weather variations (Pomoni et al. 2020a, Pomoni et al. 2020b, Do et al. 2013). Typically, increases in temperature decrease the skid resistance level. The same happens when dust is present on the surface. In addition, although the raining effect is dangerous for hydroplaning, it can also clean the pavement surface from the remaining dust and vehicle oils (contaminants) and provide a clean surface with increased skid resistance levels (Figure 2) (Plati et al. 2020b, Pomoni et al. 2020b).

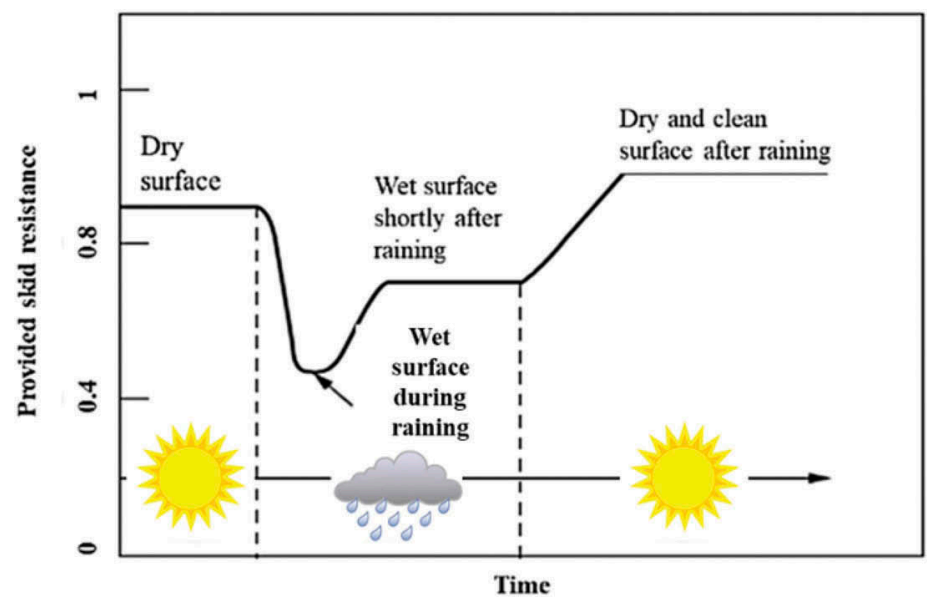

Figure 2. Typical changes in skid resistance levels due to weather changes.

Considering the above, it should be acknowledged that the use of conventional HMA in wearing courses as a standard practice, has been investigated in several researches regarding the provided skid resistance. The introduction though of new or recycled materials into pavement engineering pinpoints the necessity to assess the contribution of these materials to the provided skid resistance levels and cover the related knowledge gaps. Hence, with regards to the above concerns, at this stage of research the focus was put on the investigation of indicative weather changes effect on the provided skid resistance.

\section{FABRICATION OF HMA \& RAP MIXES}

For the accomplishment of the laboratory-based study, asphalt mixture slabs were fabricated according to the following categories:

\subsection{HMA slab (0\% RAP addition): Slab A}

Loose hot-mix asphalt (HMA) concrete was collected before being used for layering a wearing course/antiskid surface during a road construction project. The specific HMA was an opengraded mixture with the O-5 mix designation according to the ASTM D3515-01 standard (2001). Steel slag was used into the mix design as the aggregate type and a polymer-modified bitumen of 25-55/70 grade penetration was added. The mixture contained a modified binder at a percentage of $5 \%$ by mass of the mixture. 
The mixture was compacted according to the described procedure in the CEN - EN 1269733 standard (2019). The machinery utilized for the compaction process was a rolling compactor, which is a laboratory device that simulates field compaction of asphalt materials contained in specified moulds of certain dimensions $(300 \mathrm{~mm} * 300 \mathrm{~mm} * 40 \mathrm{~mm}$ height). The amount of the asphalt mixture that was placed in the moulds depended on the maximum density of the asphalt mixture and the desired level of the air voids. After the static load of the compactor on the mixture was accomplished, a specific air void content was reached. Herein, the accomplished air voids were measured and were found around $16 \%$ using the related standard (ASTM D3203, 2017).

\section{$3.2 H M A \&$ RAP slab (30\% RAP addition): Slab B}

At this type of asphalt mixture, $30 \%$ of RAP was used combined with the loose HMA as described above, in a percentage of $70 \%$. The utilized RAP material had similar properties with the HMA, but it aged more than 5 years until the time of the road rehabilitation activities when it was moved out and collected for the research purpose.

The mixture was heated in an oven and a low amount of asphalt bitumen was added $(1-2$ $\%$ approximately). Both original HMA and RAP were mixed properly to produce a homogeneous mixture, which was thereafter compacted with the rolling compactor. The achieved air void content was 9\% (ASTM D3203, 2017).

\subsection{HMA \& RAP slab (10\% RAP addition in the form of fine aggregates): Slab C}

The specific type of asphalt mixture included $10 \%$ of RAP combined with the loose HMA in a percentage of $90 \%$. However, differently from the previous mixture, the RAP material was finer, as only the fine aggregates of the RAP were added in the mixture. More specifically, only the material with aggregate size lower than $4 \mathrm{~mm}$ was added in order to assess how this kind of variation could affect the provided skid resistance. By following the same process as previously described for mixing and compacting the HMA and RAP material, the achieved air-void content was found to be 7\% (ASTM D3203, 2017).

\section{EXPERIMENTAL PROCESS}

\subsection{Weather conditions simulation}

Regarding the weather changes that affect skid resistance levels, it was attempted to develop a procedure in order to simulate some basic weather conditions that can occur in the field. As an overview, both dry and wet surfaces were examined under the conditions described in Figure 3.

The first part of the investigation was dedicated to the assessment of temperature changes. Hence, the temperatures of 10,20 and $30^{\circ} \mathrm{C}$ were simulated in order to investigate skid resistance variations against these temperature changes. The desired temperature was each time achieved through proper air-conditioning of the area surrounding the slabs as well as through a temperature-controlled chamber where the slabs were stored. Prior to measurements, a small amount of water was rinsed on the surface of the slabs as described in the British Pendulum Tester BPT standard (ASTM E303- 93, 2018).

In the second part of the investigation, the presence of water and dust on pavement surfaces was simulated at three stages. The temperature was kept constant at $20{ }^{\circ} \mathrm{C}$, as this temperature can be in general observed annually in southern European countries. At first, the slabs were totally dry and clean and then, a small amount of water was rinsed on the fabricated surfaces to simulate the condition after a short rainfall event on a clean road surface (Figure $4 a$ ).

Thereafter, the water was naturally removed from the slab and a new mixture of both dust (limestone-based) and water was placed on the surface to simulate the presence of contamination. This type of contamination can be formed after a long dry period when an immediate 


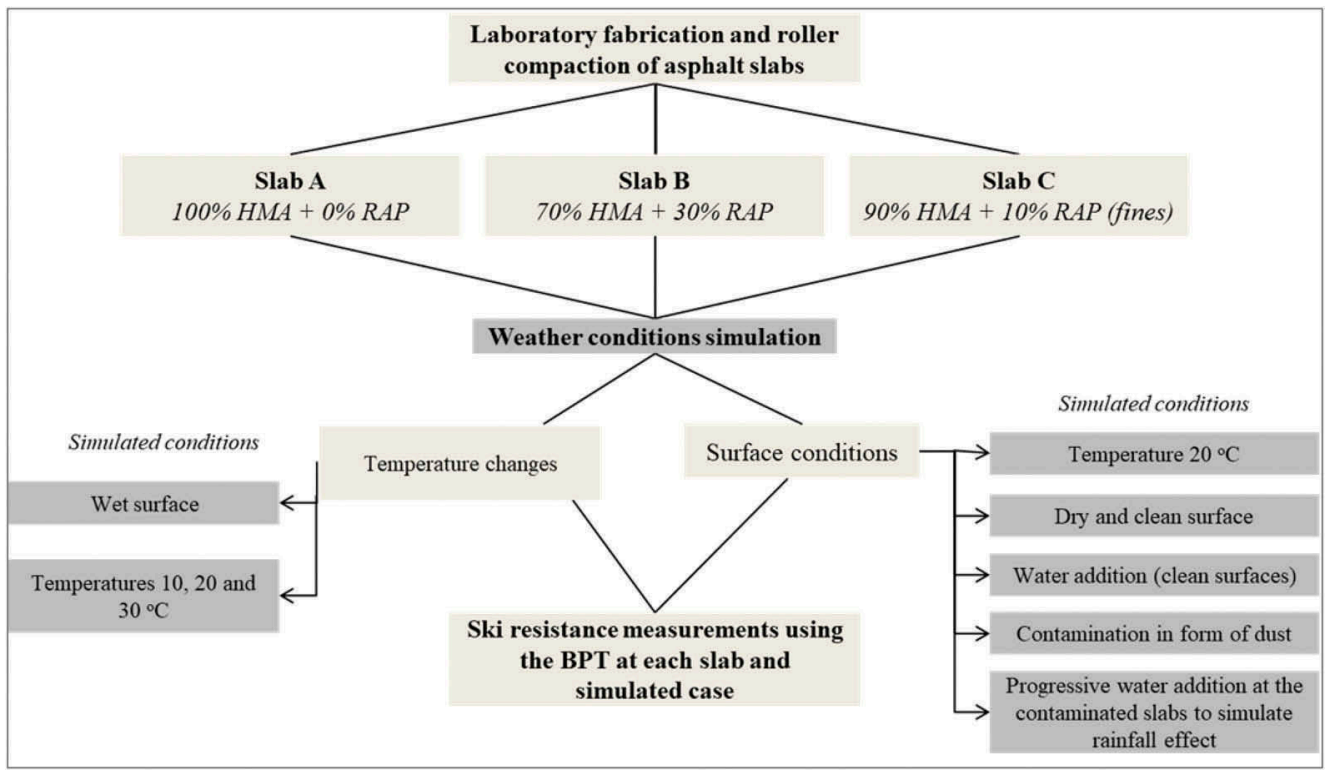

Figure 3. Experimental framework.
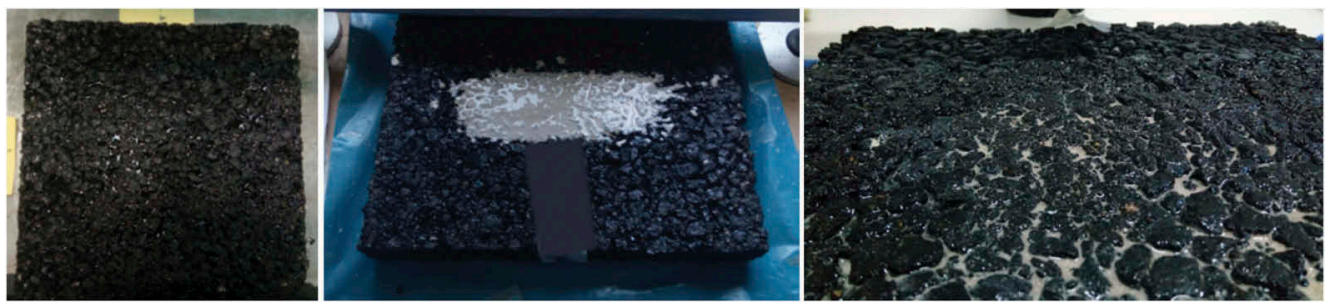

Figure 4. (a) Wet and clean surface (b) Contaminated surface (c) Contaminated surface after the rainfall simulation.

short rainfall occurs producing a slippery and contaminated surface (Figure 4b). Finally, a continuous rainfall event was simulated by rinsing a certain amount of water for a couple of minutes on the contaminated surfaces (Figure 4c).

\subsection{Skid resistance measurements}

The BPT was utilized to measure the provided skid resistance under the afore-mentioned conditions. The BPT system is a portable friction device developed in the 1960s in the United Kingdom. It is a static device and its use is standardized (ASTM E303-93, 2018). A smooth rubber slider mounted on the pendulum arm is released from the horizontal position. The slider reaches a certain speed $(\sim 10 \mathrm{~km} / \mathrm{h}$, by gravity) when the rubber touches the road surface. The output of each test is the British Pendulum Number (BPN). Zero BPN value corresponds to a totally smooth surface while $150 \mathrm{BPN}$ is the upper limit, representing practically an abnormal rough surface.

It has to be also mentioned that in many studies, the BPN index has been connected with the microtexture of a surface rather than the provided skid resistance (Pomoni et al. 2020, Pratico and Astolfi 2017). However, under the framework of the particular study where new surfaces were tested, microtexture is more critical (Plati and Pomoni 2019, Vaiana et al. 2012). 
Thus, by measuring the microtexture component, a good indication for the skid resistance level can be provided, as well.

At each of the simulated conditions described in section 3.1, BPN measurements were conducted. The average of four measurements per each condition corresponded to the characteristic BPN values that are presented in the following section.

\section{RESULTS}

At first, the impact of temperature on the provided skid resistance levels of the three slabs is assessed (Figure 5).

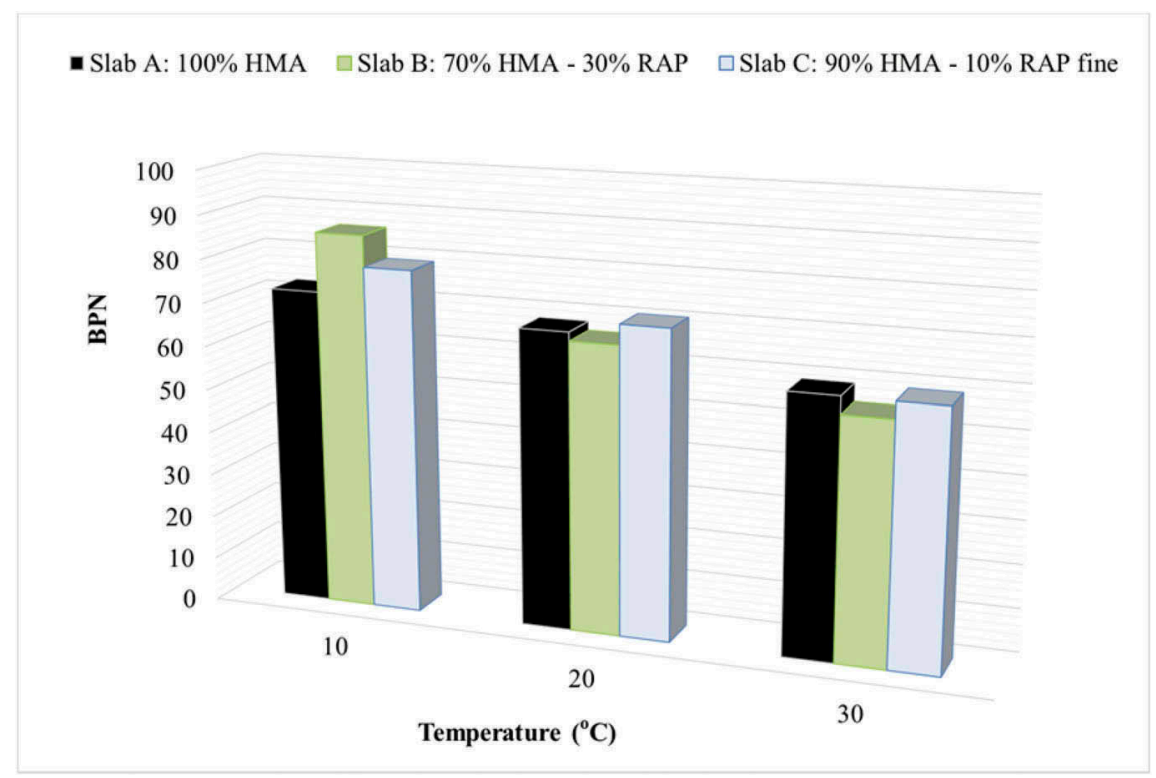

Figure 5. BPN and temperature changes.

It can be seen that a temperature increase decreases skid resistance, something which is in accordance with previously existing knowledge (Kogbara et al. 2016, Srirangam et al. 2015). This remark is valid for all the RAP contents under consideration. In particular, the rate of decrease appeared to be more intense for the slab B that consists of RAP at a percentage of $30 \%$. Also, the addition of RAP seems to be more influencing for the BPN levels at the temperature of $10{ }^{\circ} \mathrm{C}$. This result may be connected with the differences in air void content of the mixtures which might be critical for the low temperatures.

Regarding the second part of the investigated simulated weather changes, the BPN values are presented for each slab at Figures 6-8. At each figure, the horizontal axis represents the condition of the slab surface, as water mass was progressively added during the experiments. 


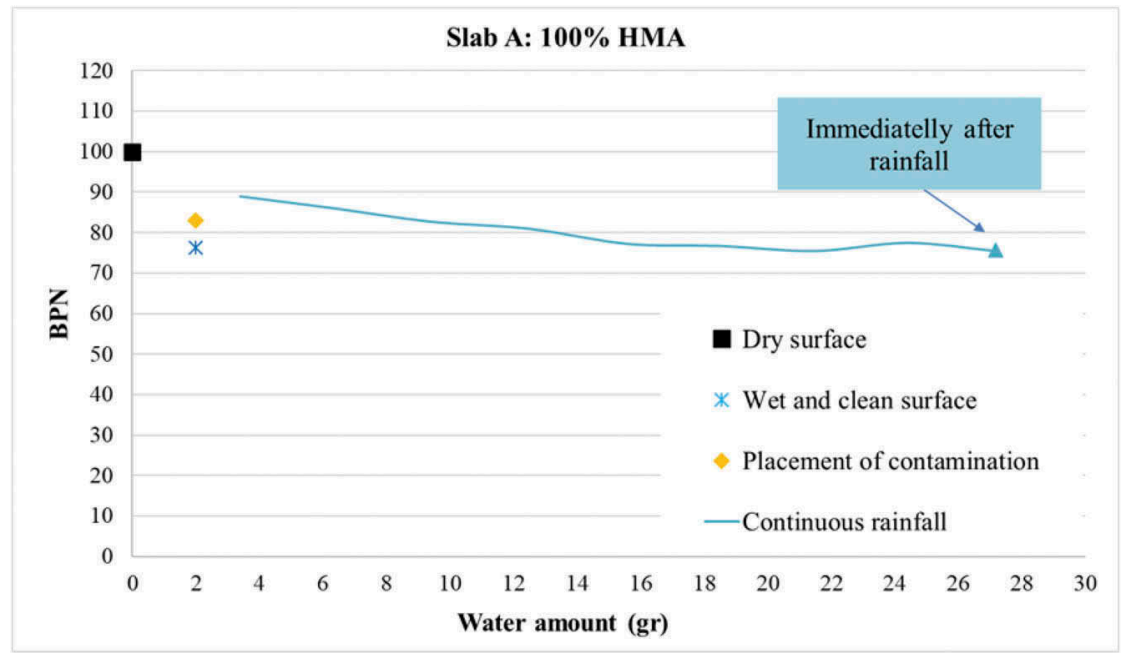

Figure 6. Skid resistance performance of slab A (100\% HMA and 0\% RAP) against weather changes.

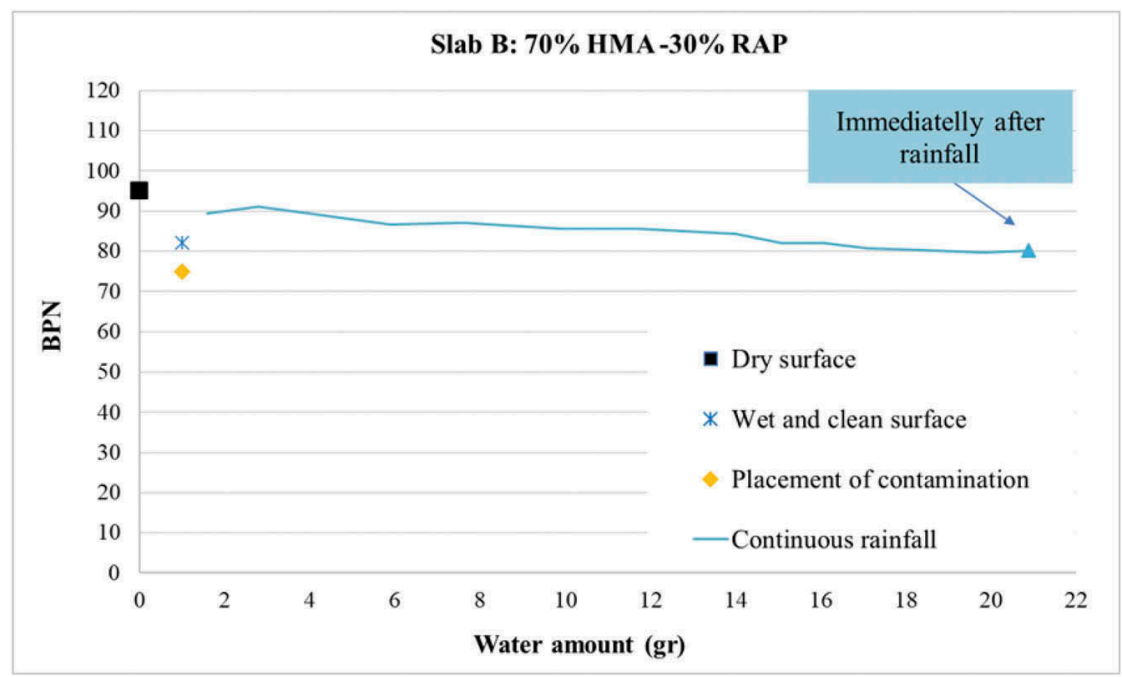

Figure 7. Skid resistance performance of slab B (70\% HMA and 30\% RAP) against weather changes.

For all the fabricated slabs, skid resistance is higher when the surfaces are dry. The HMA surface presents the greater values, something which is expected due to the increased air void content that provides a rougher surface than the other slabs with lower air void contents.

Moreover, the addition of water tends to reduce the skid resistance level. However, the slabs performance against contamination is not similar. An opposite trend can be observed in the relationship between the wet, clean and contaminated surface in slab A (Figure 6) as opposed to slabs B and C (Figures 7 and 8). The placement of contamination in the surface totally made by HMA increases the BPN levels and this is probably connected with the highest air void content $(17 \%)$ of slab A. Due to the high air voids, the mix of water and dust inserts into them, so it does not drastically intervene with the BPT slider-pavement surface contact. On the contrary, this process is not facilitated at the RAP-based slabs. Due to the lower air voids, the mix of water and dust cannot 


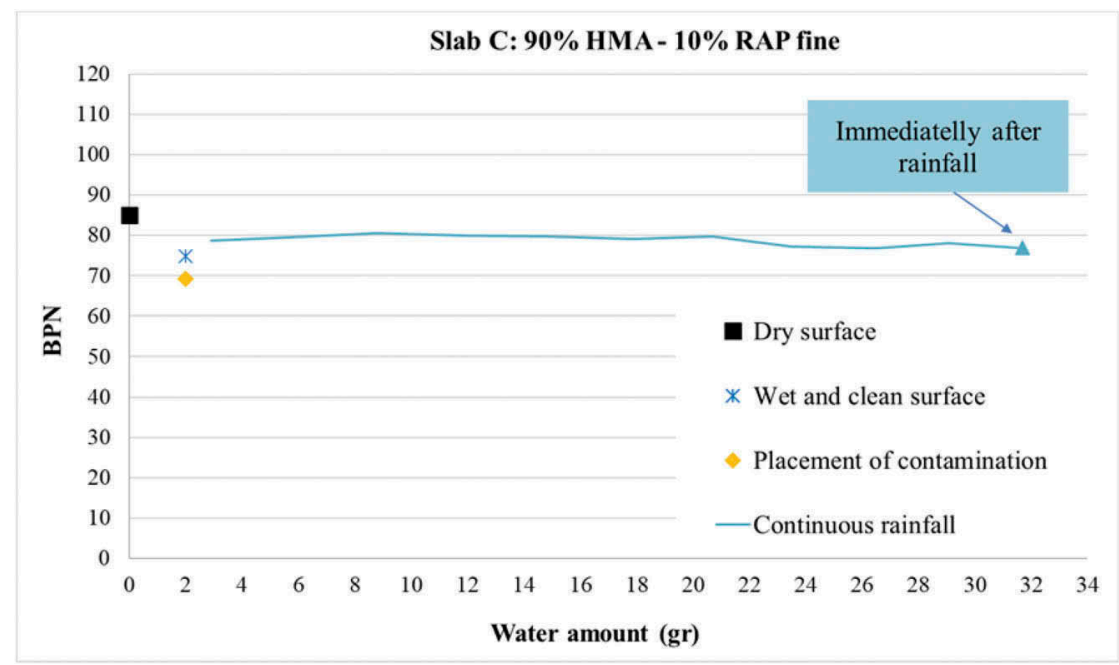

Figure 8. Skid resistance performance of slab C ( $90 \% \mathrm{HMA}$ and $10 \% \mathrm{RAP})$ against weather changes.

penetrate into the slabs, and as a consequence remains between the BPT slider-pavement contact.

Afterwards, as rainfall starts cleaning the contaminated surfaces, a better skid resistance level is observed for each slab. However, it has to be pinpointed that the BPN in slabs B and $\mathrm{C}$ does not significantly vary during the simulated continuous rainfall event, probably due to the fact that air voids are blocked by the trapped contamination. This phenomenon is more profound for the case of slab C. In particular, the slope of the curve in slab $\mathrm{C}$ is practically near zero, since both the presence of RAP fines as well as its lower air void content did not enable the contamination runoff. On the other hand, the HMA surface present greater changes in the BPN values shortly after the initiation of the rainfall, because part of the contamination may run off through the air voids faster and more effectively, in comparison with the other two slabs.

A final remark is that at the end of the rainfall simulation, a lower BPN value was measured in slab A than slabs B and C. This observation may produce evidence that RAP-based mixtures could exhibit an equally satisfactory behavior in terms of their skid resistance performance. However, further research is needed to make reliable remarks.

\section{CONCLUSION}

In the present study, it was proved that the addition of RAP did not provide negative effect on the skid resistance levels for the simulated conditions. This seems as an additional merit in its use apart from the low carbon footprint, in opposition to the new HMA mixes. Also, the air void content seemed to be critical both for the temperature changes as well as the simulated surface conditions (rainfall etc.) The high air void content provided a rougher surface with higher skid resistance values as it facilitated the water runoff during the simulated rainfall events.

In respect to the argument that the usage of the BPT device has been connected more with the provided microtexture rather than the skid resistance performance, it can be stated that the effect of macrotexture was not totally ignored within this study. Since the air void content that is absolutely connected with the provided macrotexture, appeared to affect the provided skid resistance at the investigated slabs, it can be argued that macrotexture and its influence were indirectly taken into consideration as well. 
Overall, the study highlighted the need to assess skid resistance performance of the asphalt mixtures containing recycled materials. Besides their structural soundness, roads are expected to be serviceable and safe for road users depending among others, on the provided skid resistance. Future research steps include the combined consideration of both the traffic and weather conditions effect on the provided skid resistance levels of pavement surfaces with recycled materials. Since accelerated pavement testing is not a feasible solution for preliminary testing, the potential of using these materials at wearing courses could be reliably assessed through extensive laboratory investigations that can act as a basis for future applications in the field.

\section{ACKNOWLEDGEMENT}

The research was conducted at the premises of the Laboratory of Pavement Engineering of the National Technical University of Athens (NTUA). This research is co-financed by Greece and the European Union (European Social Fund- ESF) through the Operational Programme 'Human Resources Development, Education and Lifelong Learning' in the context of the project "Strengthening Human Resources Research Potential via Doctorate Research" (MIS5000432), implemented by the State Scholarships Foundation (IKY).

\section{REFERENCES}

Al-Qadi, I.L., Elseifi, M. and Carpenter, S.H., 2007. Reclaimed asphalt pavement-a literature review. Report no. FHWA-ICT-07-001. Rantoul, IL: Illinois Center for Transportation.

ASTM D3203/D3203M-17, 2017. Standard Test Method for Percent Air Voids in Compacted Asphalt Mixtures. ASTM International, West Conshohocken, PA.

ASTM D3515-01, 2001. Standard Specification for Hot-Mixed, Hot-Laid Bituminous Paving Mixtures. ASTM International, West Conshohocken, PA.

ASTM E303-93, 2018. Standard Test Method for Measuring Surface Frictional Properties Using the British Pendulum Tester. ASTM International, West Conshohocken, PA.

CEN - EN 12697-33, 2019. Bituminous mixtures - Test method - Part 33: Specimen prepared by roller compactor, p. 22

Do, M.-T., Cerezo, V., Beautru, Y. and Kane, M., 2013. Modeling of the connection road surface microtexture/water depth/friction. Wear, 302(1-2): 1426-1435.

FHWA, 2011. Reclaimed Asphalt Pavement in Asphalt Mixtures: State of the Practice. Federal Highway Administration, Publication No. FHWA -HRT-11-021, April 2011.

Flintsch, G.W., de Leon, E., McGhee, K.K. and Najafi, S., 2012. The Little Book of Tire Pavement Friction. Pavement Surface Properties Consortium, 2012, Version 1.

Kane M. and Edmondson, V., 2020. Long-term skid resistance of asphalt surfacings and aggregates' mineralogical composition: Generalisation to pavements made of different aggregate types. Wear, https:// doi.org/10.1016/j.wear.2020.203339.

Kogbara, R.B., Masad, E.A., Kassem, E., Scarpas A.T. and Anupam, K., 2016. A state-of-the-art review of parameters influencing measurements and modeling of skid resistance of asphalt pavements. Construction and Building Materials, 114, 602-617.

Plati, C. and Pomoni, M., 2019. Impact of traffic volume on pavement macrotexture and skid resistance long-term performance. Transportation Research Record: Journal of Transportation Research Board, 2673(2): 314-322.

Plati, C., Pomoni, M., Loizos, A. and Yannis, G., 2020a. Stochastic prediction of short-term friction loss of asphalt pavements: a traffic dependent approach. In the Proceedings of the 9th International Conference on Maintenance and Rehabilitation of Pavements (Mairepav9), Raab C. (eds), Lecture Notes in Civil Engineering, vol 76. Springer, Cham. https://doi.org/10.1007/978-3-030-48679-2_86

Plati, C., Pomoni, M. and Georgouli, K., 2020b. Quantification of skid resistance seasonal variation in asphalt pavements. Journal of Traffic and Transportation Engineering, 7(2): 237-248.

Plati, C., Pomoni, M. and Stergiou, T., 2017. Development of Mean Profile Depth to Mean Texture Depth Shift Factor for Asphalt Pavements. Transportation Research Record: Journal of Transportation Research Board, 2641(1): 156-163.

Plati, C., Pomoni, M. and Stergiou, T., 2019. From Mean Texture Depth to Mean Profile Depth: Exploring possibilities. In the Proceedings of 7 th International Conference on Bituminous Mixtures and 
Pavements (7ICONFBMP), Nikolaides \& Manthos (eds), Taylor \& Francis, pp. 639-644, June 12-14, 2019, Thessaloniki, Greece, http://dx.doi.org/10.1201/9781351063265-86.

Pomoni, M., Plati, C., Loizos, A. and Yannis, G., 2020a. Investigation of pavement skid resistance and macrotexture on a long-term basis. International Journal of Pavement Engineering, https://doi.org/ 10.1080/10298436.2020.1788029.

Pomoni, M., Plati, C. and Loizos, A., 2020b. How Can Sustainable Materials in Road Construction Contribute to Vehicles' Braking? Vehicles, 2(1), 55-77, https://doi.org/10.3390/vehicles2010004.

Pratico, F.G. and Astolfi, A., 2017. A new and simplified approach to assess the pavement surface microand macrotexture. Construction and Building Materials, 148: 476-483.

Sotoodeh-Nia, Z., Manke, N., Williams, R.C., Cochran, E.W., Porot, L., Chailleux, E., Lo Presti, D., Carrión, A. and Blanc, J., 2019. Effect of two novel bio-based rejuvenators on the performance of 50\% RAP mixes - a statistical study on the complex modulus of asphalt binders and asphalt mixtures. Road Materials and Pavement Design, https://doi.org/10.1080/14680629.2019.1661276.

Srirangam, S.K., Anupam, K., Scarpas, A. and Kasbergen, C., 2015. Development of a thermomechanical tyre-pavement interaction model. International Journal of Pavement Engineering, 16(8): 721-729.

Vaiana, R., Capiluppi, G.F., Gallelli, V., Iuele, T. and Minani, V., 2012. Pavement Surface Performances Evolution: An Experimental Application. Procedia - Social and Behavioral Sciences, 53: 1149-1160.

White, G., Ward, C. and Jamieson, S., 2019. Field evaluation of a handheld laser meter for pavement surface macro texture measurement. International Journal of Pavement Engineering, https://doi.org/ $10.1080 / 10298436.2019 .1654103$. 